\title{
PENGARUH SIKAP DAN NORMA SUBYEKTIF TERHADAP NIAT BELI MAHASISWA SEBAGAI KONSUMEN POTENSIAL PRODUK PASTA GIGI CLOSE UP
}

\author{
Murwanto Sigit \\ Fakultas Ekonomi Universitas Islam Indonesia
}

\begin{abstract}
Abstrak
Penelitian ini bertujuan untuk menganalisis pengaruh secara langsung dari sikap konsumen dan norma subyektif terhadap niat untuk membeli produk pasta gigi Close Up. Hipotesis yang diajukan dalam penelitian ini adalah a) diduga sikap konsumen dan norma subyektif konsumen secara bersama-sama berpengaruh terhadap niat beli, b) diduga sikap konsumen secara parsial berpengaruh terhadap niat beli, dan c) diduga norma subyektif konsumen secara parsial berpengaruh terhadap niat beli.

Sampel ditentukan dengan metode convenience sampling dari populasi mahasiswa Universitas Islam Indonesia. Data primer dikumpulkan menggunakan kuesioner melalui survey. Sampel penelitian terdiri dari 100 mahasiswa Universitas Islam Indonesia yang belum pernah membeli produk pasta gigi Close Up. Analisis data dilakukan dengan menggunakan Regresi Linear Berganda.

Hasil penelitian menunjukkan bahwa a) sikap dan norma subyektif secara bersama-sama (simultan) berpengaruh terhadap niat beli, b) sikap konsumen secara parsial berpengaruh terhadap niat beli, dan c) norma subyektif secara parsial berpengaruh terhadap niat beli.
\end{abstract}

Kata kunci: sikap, norma subyektif, niat beli

\section{LATAR BELAKANG}

Industri pasta gigi di Indonesia dikuasai oleh beberapa merek besar yaitu Pepsodent, Close Up, Formula, Maxam, Ciptadent, Smile Up, dan Ritadent. (www.swa.co.id). Unilever menempatkan dua produknya, Pepsodent dan Close Up dalam industri ini. Pepsodent masuk ke segmen keluarga, sedangkan Close Up diperuntukkan bagi kalangan anak muda. Pepsodent merajai segmen keluarga, sedangkan Close Up merajai segmen anak muda (www.swa.co.id).

Menurut Kotler (2000:451), pasta gigi merupakan produk consumer goods yang berdasarkan kebiasaan pembelian konsumennya dapat digolongkan menjadi convenience goods, yaitu produk yang dibeli dan dipakai secara teratur (staples). Berdasarkan durability-nya, pasta gigi merupakan produk nondurable yaitu produk yang digunakan sekali pakai.

Strategi pemasaran yang paling cocok untuk kategori produk ini adalah dengan menjaga ketersediaan produk di banyak lokasi (outlet), menetapkan margin keuntungan yang kecil agar harga penjualan tidak terlalu tinggi, dan gencar beriklan untuk mendorong preferensi merek dan niat menggunakan atau mencobanya (Kotler, 2000). 
Mengingat tingkat persaingan di pasar pasta gigi (industri toiletries) yang terus meningkat yang ditandai dengan makin seringnya produsen lama mengembangkan produk dan munculnya pemain baru, maka produsen pasta gigi perlu untuk menyelami lebih jauh tentang karakteristik konsumen mereka. Dalam hal ini, produsen perlu bertindak sebagai konsumen untuk mengetahui benar apa yang diinginkan oleh konsumennya.

Salah satu kunci sukses dari strategi pemasaran adalah pengembangan produk dan promosi yang sesuai dengan kebutuhan target pasar. Dengan demikian produk yang berhasil adalah produk yang dapat diterima konsumen dengan harga, atribut dan tampilan yang memenuhi kebutuhan konsumen. Untuk itu produsen perlu mengetahui bagaimana konsumen memandang produk-produk dan progam pemasarannya. Bagi perusahaan tanggapan konsumen terhadap produk yang dihasilkannya adalah sangat penting, termasuk penilaian konsumen terhadap atribut-atribut produk. Penilaian konsumen ini akan mempengaruhi niat konsumen. Niat merupakan satu faktor internal (individual) yang mempengaruhi perilaku konsumen, niat adalah suatu bentuk pikiran yang nyata dari refleksi rencana pembeli untuk membeli beberapa unit dalam jumlah tertentu dari beberapa merek yang tersedia dalam periode waktu tertentu (Schiffman dan Kanuk, 2000: 206). Dalam proses pembelian, niat beli konsumen ini berkaitan erat dengan motif yang dimilikinya untuk memakai ataupun membeli produk tertentu. Motif pembelian ini berbeda-beda untuk setiap konsumen.

Konsumen akan memilih produk yang mengandung atribut-atribut yang diyakininya relevan dengan yang dibutuhkannya. Penilaian konsumen terhadap atribut produk tergantung pada pengetahuannya akan informasi tentang fungsi sebenarnya dari atribut produk tersebut, dengan demikian niat beli konsumen terhadap suatu produk secara tidak langsung dipengaruhi oleh pengetahuannya akan informasi atribut suatu produk (Kotler, 2000: 205).

Menurut Theory of Reasoned Action dari Fishbein dan Aizen, tindakan seseorang adalah realisasi dari keinginan atau niat seseorang untuk bertindak. Faktor yang mempengaruhi niat adalah sikap pada tindakan, dan norma subyektif menyangkut persepsi seseorang, apakah orang lain yang dianggap penting akan mempengaruhi perilakunya (Dharmmesta, 1998).

Niat beli mahasiswa UII sebagai konsumen potensial pada pasta gigi Close Up yang dipengaruhi Sikap Konsumen dan Norma Subyektif Konsumen menarik untuk diteliti, karena produk ini merupakan leader untuk segmen anak muda (www.swa.co.id).

\section{REASONED ACTION THEORY}

Model ini juga disebut sebagai model niat pembelian Fishbein atau model perluasan dari model sebelumnya, yaitu Fishbein's attitude model. Theory of reasoned action menggambarkan keterpaduan yang menyeluruh dari komponen sikap dalam struktur yang didisain untuk mengarahkan prediksi dan penjelasan yang 
lebih baik dari perilaku (Schiffman dan Kanuk, 2000: 206). Model ini memandang perilaku seseorang sebagai fungsi dari niatnya untuk berperilaku dalam cara tertentu dan variabel penguat lainnya (intervening). Bahwa niat seseorang untuk membeli suatu produk $(\mathrm{BI})$ dipengaruhi oleh sikapnya terhadap perilaku atau tindakan pembelian tersebut $(A B)$ dan norma subyektifnya (SN) dimana persepsi seseorang bahwa orang lain yang penting baginya akan bertindak terhadap perilaku itu. Sebagai fungsi model tersebut dapat dinyatakan sebagai berikut:

$$
B \boldsymbol{I}=\int(A b, S n)
$$

Jelasnya teori Fishbein dan Ajzen menyatakan bahwa sikap dan norma subyektif bersama-sama menentukan niat pembelian terhadap suatu produk (Dharmmesta, 1998). Hubungan ini dijelaskan dalam persamaan sebagai berikut:

$$
B \sim B I=w_{1}\left(A_{b}\right)+w_{2}(S N)
$$

Dimana:

$\mathrm{B} \quad=$ perilaku aktual seseorang yang merupakan fungsi BI (tindakan pembelian)

$\mathrm{BI} \quad=$ Niat berperilaku (Niat untuk melakukan pembelian)

〜 = Menunjukkan kedua variabel B dan BI dapat berhubungan.

$A_{b} \quad=$ sikap terhadap perilaku pembelian.

$\mathrm{SN}=$ norma subyektif berkaitan dengan perilaku pembelian.

$\mathrm{W}_{1}, \mathrm{~W}_{2}=$ bobot yang menggambarkan pengaruh relatif dari $A_{b}$ dan $S N$.

sementara sikap individu terhadap tindakan perilaku spesifik $\left(A_{b}\right)$ dinyatakan sebagai berikut:

$$
A b=\sum b i . e i
$$

dimana:

$\mathrm{Ab}=$ sikap individu terhadap perilaku pembelian.

$b_{\mathrm{i}} \quad=$ keyakinan seseorang bahwa jika melakukan perilaku tertentu akan berkonsekuensi tertentu pula.

$\mathrm{e}_{\mathrm{i}} \quad=$ evaluasi seseorang terhadap konsekuensi yang akan ditanggung.

Kemudian komponen norma subjektif dapat dinyatakan sebagai berikut:

$$
S N=\sum n b j . m c j
$$

dimana:

$\mathrm{SN}=$ norma subyektif individual berkaitan dengan perilaku spesifik.

$n b_{j}=$ keyakinan normatif bahwa kelompok acuan atau orang lain yang dianggap penting berpikir sebaiknya melakukan atau tidak melakukan tindakan tertentu tersebut.

$\mathrm{mc}_{\mathrm{j}}=$ motivasi seseorang untuk mematuhi pikiran kelompok acuan yang dianggap penting. 


\section{MODEL PENELITIAN}

Berdasarkan theory of reasoned action yang digunakan dalam penelitian ini, dapat dibuat grafis hubungan antar variabel penelitian yang terdapat pada Gambar berikut:

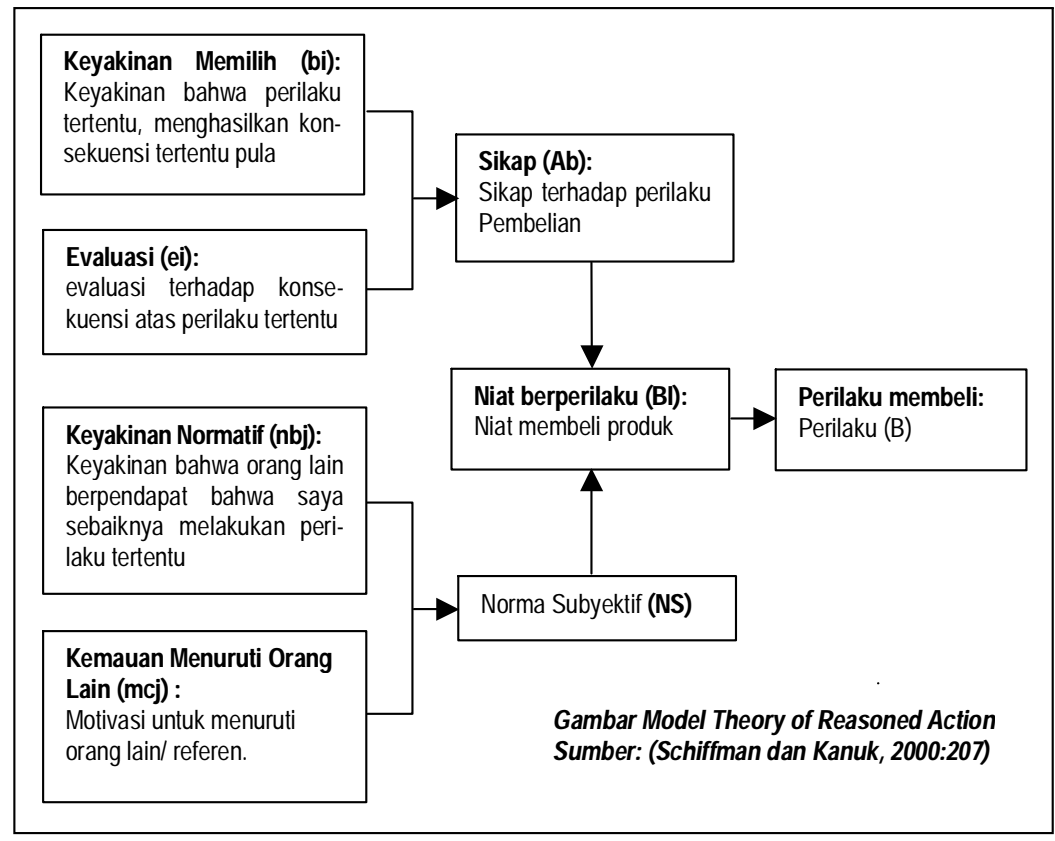

\section{PENGEMBANGAN HIPOTESIS}

Hipotesis yang digunakan dalam penelitian ini dirumuskan berdasarkan Reasoned Action Theory dari Ajzen dan Fishbein. Hipotesis dirumuskan berdasarkan hubungan linear searah dari variabel sikap konsumen dan variabel norma subyektif dalam mempengaruhi niat konsumen untuk membeli produk, karena ada dua variabel independent (sikap dan norma subyektif) yang mempengaruhi satu variabel dependen (niat membeli), maka ada tiga hipotesis yang dapat dirumuskan, dua hipotesis dirumuskan untuk pengaruh parsial (secara sendiri-sendiri) dari variabelvariabel independent (sikap dan norma subyektif) terhadap variabel dependen (niat membeli) dan satu hipotesis dirumuskan untuk pengaruh simultant (secara bersamasama) dari variabel-variabel independent (sikap dan norma subyektif) terhadap variabel dependen (niat membeli). Hasil dari perumusan hipotesis adalah sebagai berikut:

Ho1 = diduga sikap konsumen dan norma subyektif konsumen secara bersamasama tidak berpengaruh terhadap niat beli. 
Ha1 = diduga sikap konsumen dan norma subyektif konsumen secara bersamasama berpengaruh terhadap niat beli.

Ho2 = diduga sikap konsumen secara parsial tidak berpengaruh terhadap niat beli.

Ha2 = diduga sikap konsumen secara parsial berpengaruh terhadap niat beli.

Ho3 = diduga norma subyektif konsumen secara parsial tidak berpengaruh terhadap niat beli.

Ha3 = diduga norma subyektif konsumen secara parsial berpengaruh terhadap niat beli.

\section{METODE PENELITIAN}

\section{Jenis Penelitian}

Jenis penelitian yang digunakan oleh penulis adalah penelitian survey yaitu pengumpulan informasi secara sistematik dari responden dengan maksud untuk memahami aspek perilaku dari populasi yang diteliti (Sekaran, 2000: 249). Penulis menganalisis data-data yang diperoleh dari responden berdasarkan kuesioner yang telah disusun.

\section{Populasi}

Populasi adalah jumlah dari keseluruhan orang, kejadian, atau sesuatu yang ingin diteliti (Sekaran, 2000: 266). Populasi dalam penelitian ini adalah mahasiswa Universitas Islam Indonesia Yogyakarta yang merupakan konsumen potensial dari produk pasta gigi Close Up.

\section{Sampel}

Sampel adalah bagian dari populasi yang terdiri dari sejumlah anggota terpilih dari populasi. Sampel harus mewakili populasinya, sehingga kesimpulan mengenai populasi yang tepat dapat dihasilkan (Sekaran, 2000: 267). Sampel dalam penelitian ini adalah 100 mahasiswa Universitas Islam Indonesia Yogyakarta yang merupakan konsumen potensial dari produk pasta gigi Close Up.

Penarikan sampel adalah proses memilih jumlah yang cukup dari populasi untuk mempelajari dan memahami karakteristik dari subyek sampel sehingga peneliti dapat menggeneralisasikan karakter dari elemen populasi (Sekaran, 2000: 267). Metode pengambilan sampel yang digunakan dalam penelitian ini adalah nonprobability sampling. Pada metode ini tidak semua unsur dalam populasi mempunyai kesempatan yang sama untuk menjadi sampel penelitian. Jenis non-probability sampling yang digunakan adalah convenience sampling, yaitu mengumpulkan informasi dari anggota populasi yang paling mudah didekati dan didapatkan. Menurut Sekaran (2000:277) ukuran sampel lebih dari 30 dan kurang dari 500 sudah representatif untuk kebanyakan penelitian survey. Pengambilan sampel secara convenience dilakukan dengan cara membagi kuesioner kepada mahasiswa UII yang kebetulan sedang berada di kampus Condong Catur, Kaliurang, dan Taman Siswa. 


\section{Metode Pengumpulan Data}

Data primer dikumpulkan dengan instrumen berupa kuesioner isian (angket) yang bersifat tertutup, dimana responden menjawab pertanyaan dengan memilih alternatif jawaban sesuai dengan pendapatnya (closed questioner). Kuesioner dikembangkan dari model Fishbein dan Ajzen (Dharmmesta, 1997: 3). Semua variabel diukur dengan menggunakan Skala Likert (Skala 1-5).

\section{HASIL PENELITIAN}

Berdasarkan Tabel 1 diketahui bahwa nilai corrected item-total correlations semua butir pertanyaan dalam kuesioner adalah valid, baik item pertanyaan dalam variabel Sikap yang dibentuk dari variabel Keyakinan dan variabel Evaluasi, maupun variabel Norma Subyektif yang dibentuk dari variabel Keyakinan Normatif dan variabel Motivasi Menuruti Referen. Variabel Niat Beli hanya memiliki satu item pertanyaan saja, jadi secara otomatis pertanyaan tersebut dinyatakan valid. Semua skor corrected item-total correlations berada di atas angka 0,3 yang menjadi pedoman angka minimal untuk menyatakan kevalidan (Nawawi, 1998:137).

Tabel 1: Tabel Validitas Instrumen Penelitian pada Survei

\begin{tabular}{|c|c|c|c|c|}
\hline No & Variabel & Item Pertanyaan & $\begin{array}{c}\text { Corrected Item-Total } \\
\text { Correlation }\end{array}$ & Keterangan \\
\hline \multirow{7}{*}{1.} & \multirow{7}{*}{ Keyakinan } & Keyakinan 1 & 0,5006 & Valid \\
\hline & & Keyakinan 2 & 0,5051 & Valid \\
\hline & & Keyakinan 3 & 0,6672 & Valid \\
\hline & & Keyakinan 4 & 0,6958 & Valid \\
\hline & & Keyakinan 5 & 0,5424 & Valid \\
\hline & & Keyakinan 6 & 0,4273 & Valid \\
\hline & & Keyakinan 7 & 0,4599 & Valid \\
\hline \multirow{7}{*}{2.} & \multirow{7}{*}{ Evaluasi } & Evaluasi 1 & 0,7080 & Valid \\
\hline & & Evaluasi 2 & 0,6596 & Valid \\
\hline & & Evaluasi 3 & 0,7479 & Valid \\
\hline & & Evaluasi 4 & 0,7022 & Valid \\
\hline & & Evaluasi 5 & 0,7024 & Valid \\
\hline & & Evaluasi 6 & 0,4875 & Valid \\
\hline & & Evaluasi 7 & 0,5951 & Valid \\
\hline \multirow{3}{*}{3.} & \multirow{3}{*}{ Keyakinan Normatif } & Key. Norm. 1 & 0,7111 & Valid \\
\hline & & Key. Norm. 2 & 0,7394 & Valid \\
\hline & & Key. Norm. 3 & 0,5472 & Valid \\
\hline \multirow{3}{*}{4.} & \multirow{3}{*}{$\begin{array}{l}\text { Motivasi Menuruti } \\
\text { Referen }\end{array}$} & Menrt Ref. 1 & 0,7950 & Valid \\
\hline & & Menrt Ref. 2 & 0,8125 & Valid \\
\hline & & Menrt Ref. 3 & 0,7878 & Valid \\
\hline
\end{tabular}

Sumber : Lampiran Reliabilitas dan Validitas 
Berdasarkan hasil survei dengan 100 responden ditemukan bahwa seluruh item pertanyaan dalam variabel Sikap yang dibentuk dari variabel Keyakinan dan variabel Evaluasi maupun variabel Norma Subyektif yang dibentuk dari variabel Keyakinan Normatif dan variabel Motivasi Menuruti Referen adalah reliabel, variabel Niat Beli hanya memiliki satu item pertanyaan saja, jadi secara otomatis pertanyaan tersebut dinyatakan reliabel. Hal ini didukung dengan skor alpha cronbach, variabel Keyakinan memiliki alpha 0,8034, variabel Evaluasi memiliki alpha 0,8727, variabel Keyakinan Normatif memiliki alpha 0,8108, dan variabel Motivasi menuruti Referen memiliki alpha 0,8979. Uji reliabilitas dalam penelitian ini menggunakan skor Cronbach Alpha dengan derajat kepercayaan 95\%. Reliabilitas dinyatakan dengan koefisien alpha yang mempunyai rentang antara 0 sampai 1 . Semakin mendekati angka 1 berarti semakin tinggi reliabilitasnya (Sekaran, 2000, 206).

Tabel 2: Tabel Reliabilitas Instrumen Penelitian pada Survei

\begin{tabular}{|c|l|c|c|}
\hline No & \multicolumn{1}{|c|}{ Variabel } & $\begin{array}{c}\text { Alpha } \\
\text { Cronbach }\end{array}$ & Keterangan \\
\hline 1. & Keyakinan & 0,8034 & Reliabel \\
\hline 2. & Evaluasi & 0,8727 & Reliabel \\
\hline 3. & Keyakinan Normatif & 0,8108 & Reliabel \\
\hline 4. & Motivasi Menuruti Referen & 0,8979 & Reliabel \\
\hline
\end{tabular}

Sumber : Lampiran Reliabilitas dan Validitas

Tabel 3: Hasil Regresi Linear Berganda

\begin{tabular}{|l|c|c|c|}
\hline \multicolumn{1}{|c|}{ Variabel } & Koefisien regresi & $\begin{array}{c}\text { Nilai Probabilitas Uji } \\
\mathbf{t}\end{array}$ & $\begin{array}{c}\text { Nilai Probabilitas Uji } \\
\mathbf{F}\end{array}$ \\
\hline Sikap & 0,0154 & 0,000 & 0,000 \\
\hline Norma Subyektif & 0,0123 & 0,004 & \\
\hline
\end{tabular}

$R^{2}=0,383, N=100$, Level of Significance $=0,05$

Sumber : Lampiran Regresi Linear Berganda

Uji hipotesis pertama menunjukkan bahwa ada pengaruh yang signifikan dari sikap dan norma subyektif responden secara simultan (bersama-sama) terhadap niat membeli pasta gigi Close Up, hal ini dapat dilihat dari nilai probabilitas yang dihasilkan uji $F$ regresi linear berganda adalah 0,000 jauh dibawah level of significance $(0,05)$. Uji hipotesis kedua menunjukkan bahwa ada pengaruh yang signifikan dari sikap responden secara parsial (individual) terhadap niat membeli pasta gigi Close Up, hal ini dapat dilihat dari nilai probabilitas yang dihasilkan uji t regresi linear berganda adalah 0,000 jauh dibawah level of significance $(0,05)$. Uji hipotesis ketiga menunjukkan bahwa ada pengaruh yang signifikan dari norma subyektif responden secara parsial (individual) terhadap niat membeli pasta gigi Close Up, hal ini dapat dilihat dari nilai probabilitas yang dihasilkan uji t regresi linear berganda adalah 0,004 jauh dibawah level of significance $(0,05)$. Pada prinsipnya pengambilan keputusan berdasarkan membandingkan t-hitung dan t-tabel atau membandingkan F-hitung dan 
F-tabel akan menghasilkan kesimpulan yang sama dengan berdasarkan membandingkan angka probabilitas dengan alpha. Pada umumnya penggunaan angka probabilitas lebih sering dipakai sebagai dasar pengambilan keputusan inferensi (Santoso, 2000: 163).

Koefisien regresi dari variabel Sikap adalah 0,0154, dan koefisien dari variabel Norma Subyektif adalah 0,0123, koefisien Sikap lebih besar dibandingkan koefisien Norma Subyektif, hal ini menunjukkan bahwa variabel Sikap lebih dominan mempengaruhi Niat Beli mahasiswa UII terhadap produk Close Up dibandingkan variabel Norma Subyektif.

$R$ square $\left(R^{2}\right)$ dari regresi linear berganda yang diperoleh adalah 0,383 , angka ini menjelaskan bahwa cakupan pengaruh dari Sikap dan Norma Subyektif terhadap Niat Beli adalah 38,3\%, sedangkan 61,7\% pengaruh terhadap Niat Beli dijelaskan oleh variabel lain di luar model penelitian ini.

Sikap dan Norma Subyektif yang berpengaruh signifikan terhadap Niat membeli Close Up merupakan indikator bahwa Close Up sebagai leader produk pasta gigi pada segmen anak muda sudah dapat diterima dengan baik oleh konsumen potensialnya.

Hasil penelitian ini mendukung theory of reasoned action dari Ajzen dan Fishbein yang menyatakan bahwa Niat sangat dipengaruhi oleh Sikap dan Norma Subyektif.

Tabel 4: Demografi Profil Responden

\begin{tabular}{|c|c|c|}
\hline \multicolumn{3}{|c|}{ Jenis Kelamin } \\
\hline & Frekuensi & Persentase \\
\hline Laki-laki & 65 & 65.0 \\
\hline Perempuan & 35 & 35.0 \\
\hline \multicolumn{3}{|c|}{ Usia } \\
\hline Range Usia & Frekuensi & Persentase \\
\hline$<20$ tahun & 11 & 11.0 \\
\hline $20-23$ tahun & 69 & 69.0 \\
\hline $24-26$ tahun & 17 & 17.0 \\
\hline $27-30$ tahun & 3 & 3.0 \\
\hline
\end{tabular}

Sumber : Lampiran

Jenis Kelamin

\begin{tabular}{|ll|r|r|r|r|}
\hline & Frequency & Percent & Valid Percent & \multicolumn{1}{c|}{$\begin{array}{c}\text { Cumulative } \\
\text { Percent }\end{array}$} \\
\hline Valid & Laki-laki & & & 65.0 & 65.0 \\
& Perempuan & & & 35.0 & 100.0 \\
& Total & 100 & 100.0 & 100.0 & \\
\hline
\end{tabular}


Tabel 5: Hasil Rata-rata Jawaban Responden

\begin{tabular}{|l|c|}
\hline \multicolumn{1}{|c|}{ Variabel } & Rata-rata \\
\hline Sikap & 4,44 \\
\hline Norma Subyektif & 3,37 \\
\hline Niat Beli & 4,14 \\
\hline
\end{tabular}

Sumber : Lampiran

\section{SIMPULAN}

Pertama, sikap dan norma subyektif dari mahasiswa UII secara bersamasama berpengaruh signifikan terhadap niat membeli pasta gigi Close Up. Kedua, sikap dari mahasiswa UII secara parsial berpengaruh signifikan terhadap niat membeli pasta gigi Close Up. Ketiga, norma subyektif dari mahasiswa UII secara parsial berpengaruh signifikan terhadap niat membeli pasta gigi Close Up.

\section{MANFAAT PENELITIAN}

Hasil penelitian yang mungkin berguna bagi pemasar produk pasta gigi Close Up adalah: (1) pemasar Close Up dapat lebih memperhatikan sikap konsumennya dalam menyusun strategi pemasarannya, karena penelitian ini menunjukkan bahwa sikap konsumen lebih mempengaruhi niat beli Close Up dibandingkan norma subyektifnya, (2) pemasar Close Up jangan mengabaiakan Norma Subyektif dari konsumen, meskipun pengaruhnya lebih kecil dari Sikap Konsumen dalam mempengaruhi Niat Beli, harus diingat juga bahwa Norma Subyektif secara parsial juga berpengaruh signifikan terhadap niat beli Close Up. Jadi norma subyektif konsumen tetap bisa dijadikan masukan dalam penyusunan strategi pemasaran produk Close Up.

Manfaat untuk para peneliti selanjutnya yang tertarik pada tema niat beli adalah dapat lebih memperluas variabel yang mempengaruhi niat beli, agar cakupan mengenai variabel yang mempengaruhi niat beli dapat meluas dan semoga temuantemuan baru tersebut dapat memberi sumbangan baru untuk ilmu pengetahuan bidang pemasaran.

\section{DAFTAR PUSTAKA}

Aaker, David A., V. Kumar, \& George S. Day, (1998), Marketing Research, 6 $6^{\text {th }}$ ed, John Wiley \& Sons: Inc.

Albari, \& Anita Liriswati, (2004), Analisis Minat Beli Konsumen Sabun Cair Lux, Biore, dan Lifebuoy di Kota Madya Yogyakarta Ditinjau dari Pengaruh Sikapnya Setelah Melihat Iklan di Televisi dan Norma Subyektif, Jurnal Siasat Bisnis, 2 (9): 215-239. 
Dharmmesta, Basu Swastha, (1997), Keputusan-Keputusan Strategik untuk Mengeksplorasi Sikap dan Perilaku Konsumen, Jurnal Ekonomi dan Bisnis Indonesia, 12 (3): 1-19.

Dharmmesta, Basu Swastha, (1998), Theory of Planned Behavior dalam Penelitian Sikap, Niat dan Perilaku Konsumen, Kelola 8 (7): 85-103.

Dharmmesta, Basu Swastha, \& T. Hani Handoko, (1992), Manajemen Pemasaran: Analisa Perilaku Konsumen, Edisi Pertama, Liberty: Yogyakarta.

Engel, James F., Roger D. Blackwell, \& Paul W.Miniard, (1995), Consumer Behavior, $8^{\text {th }}$ ed., The Dryden Press: Orlando.

Hadi, Sutrisno, (2000), Statistik, Andi Offset: Yogyakarta.

Hanna, Nessim, \& Richard Wozniak, (2001), Consumer Behavior: An Applied Approach, Prentice-Hall: Intenational.

Hawkins, D., Roger J. Best, \& Keneth A. Coney, (1998), Consumer Behavior: Building Marketing Strategy, $7^{\text {th }}$ ed., Mc-Graw Hill Company.

Kalafatis, Stravros D, Michael Pollard, Robert East, \& Markos H. Tsogas, (1999), Green Marketing and Ajzen's Theory Of Planned Behaviour: A CrossMarket Examinaton, Journal of Consumer Marketing, 16 (5), 1999: 441-460.

Kottler, Philip, (2000), Marketing Management: Analysis, Planning, Implementation and Control, $10^{\text {th }}$ ed. Prentice Hall: International.

Loudon, David L., \& Albert J. Della Bitta, (1993), Consumer Behavior: Concept and Application, $4^{\text {th }}$ ed., Mc-Graw Hill Book Co: New York.

Nawawi, Hadari, (1998), Metode Penelitian Bidang Sosial, cetakan kedelapan, Gadjah Mada University Press: Yogyakarta.

Rafick, Ishak, (2002), Strategi Efisiensi Gaya P\&G, SWA, Maret 2002, 05 (18): 7-20.

Ramayah, T., A.M. Nasurdin, M. Nasser Noor, \& Q. Boon Sin, (2004), The Relationship Between Belief, Attitude, Subjective Norm, and Behavior toward Infant Food Formula Selection: The Views of the Malaysian Mothers, Gadjah Mada International Journal of Business, 06 (3): 405-418.

Santosa, Singgih, (2000), SPSS: Mengolah Data Statistik Secara Profesional Ver. 7.5, PT Elex Media Komputindo: Jakarta.

Santoso, Singgih, (2002), Buku latihan SPSS Statisik Parametrik, Edisi ketiga, Gramedia: Jakarta

Sarwono, S.W., (1997). Psikologi Sosial: Individu dan Teori-Teori Psikologi Sosial, Balai Pustaka: Jakarta. 
Schiffman, Leon G., \& Leslie Lazar Kanuk (2000), Consumer Behavior, $7^{\text {th }}$ ed., Prentice Hall: International

Sekaran, Uma (2000), Research Methods For Business: A Skill-Building Approach, $3^{\text {rd }}$ ed., John Wiley \& Sons: Inc.

Temporal, Paul (2000), Branding In Asia: The Creation, Development, And Management Of Asian Brand For The Global Market, John Wiley \& Sons: Asia.

Wells, William D., \& David Prensky, (1996), Consumer Behavior, John Wiley \& Sons: Inc. www.swa.co.id 